\title{
Lenke and King classification systems for adolescent idiopathic scoliosis: interobserver agreement and postoperative results
}

This article was published in the following Dove Press journal:

International Journal of General Medicine

7 December 201I

Number of times this article has been viewed

\section{Hojjat Hosseinpour-Feizi Jafar Soleimanpour Jafar Ganjpour Sales \\ Ali Arzroumchilar}

Department of Orthopedics, Shohada Hospital, Faculty of Medicine, Tabriz University of Medical Sciences,

Tabriz, Iran
Correspondence: Hojjat Hosseinpour-Feizi 249 Koucheyeh Nosrat Nezam, Artesh-Jenoubi Avenue,

51368 Tabriz, Iran

Tel +984 II 5541939

Fax +98 4II 553 I442

Email hojjathosseinpourfeizi@yahoo.com
Purpose: The aim of this study was to investigate the interobserver agreement of the Lenke and King classifications for adolescent idiopathic scoliosis, and to compare the results of surgery performed based on classification of the scoliosis according to each of these classification systems.

Methods: The study was conducted in Shohada Hospital in Tabriz, Iran, between 2009 and 2010. First, a reliability assessment was undertaken to assess interobserver agreement of the Lenke and King classifications for adolescent idiopathic scoliosis. Second, postoperative efficacy and safety of surgery performed based on the Lenke and King classifications were compared. Kappa coefficients of agreement were calculated to assess the agreement. Outcomes were compared using bivariate tests and repeated measures analysis of variance.

Results: A low to moderate interobserver agreement was observed for the King classification; the Lenke classification yielded mostly high agreement coefficients. The outcome of surgery was not found to be substantially different between the two systems.

Conclusion: Based on the results, the Lenke classification method seems advantageous. This takes into consideration the Lenke classification's priority in providing details of curvatures in different anatomical surfaces to explain precise intensity of scoliosis, that it has higher interobserver agreement scores, and also that it leads to noninferior postoperative results compared with the King classification method.

Keywords: test reliability, scoliosis classification, postoperative efficacy, adolescents

\section{Introduction}

Idiopathic scoliosis is the most common type of spinal deformity seen in orthopedic clinics. It has a rather insidious onset and shows poor progression and results. ${ }^{1}$ Adolescent idiopathic scoliosis is a lateral curving of the spine occurring in children aged 10 years and older. It has been shown that $2 \%-3 \%$ of children under 16 years of age suffer from greater than $10^{\circ}$ of lateral deviation of the spine; however, deviations greater than $40^{\circ}$ have a prevalence rate lower than $0.1 \%{ }^{2}$ Scoliosis causes trunk asymmetry and leads to disorders of the spinal canal, neurologic disorders, cardiovascular disorders, and osteoarthritis. ${ }^{2,3}$

Proper recognition and treatment of idiopathic scoliosis helps to optimize patient outcomes. Nearly $10 \%$ of scoliosis patients undergo surgical treatment. Idiopathic scoliosis needs to be well recognized and classified to ensure optimal treatment. Patient selection for surgery is based on assessment of the intensity of the disease. Several classification systems have been developed to determine the intensity of adolescent idiopathic scoliosis; these include the Lenke and King classification systems, both of which 
are well known to orthopedic surgeons. However, because of the existing variability worldwide in setting, patient, and observer or operating surgeon, the available evidence on reproducibility and comparability of these classification systems in making decisions on surgery indications is not adequate, especially for low- and middle-income countries. The aim of this study was to investigate the interobserver agreement of Lenke and King classifications for adolescent idiopathic scoliosis, and to compare the results of surgery performed based on classification of the scoliosis according to each of these classification systems.

\section{Methods}

The study was conducted in Shohada Hospital in Tabriz, Iran, between 2009 and 2010. It comprised two parts: first, a reliability assessment was conducted to assess interobserver agreement of the Lenke and King classifications for adolescent idiopathic scoliosis; second, postoperative efficacy and safety of surgery performed based on the Lenke and King classifications were compared.

Forty sets of preoperative radiographs of patients subject to corrective surgery for idiopathic scoliosis in the orthopedic ward of Shohada Hospital were selected for the study. For the first part of the study, three observers, all spine surgeons, classified each of these radiographs independently and according to both the Lenke and the King classifications. The radiograph sets were presented to the observers in a randomized sequence and without personal identifiers. Care was taken to guarantee blind assessment through the erasing of names and identifiers, which were replaced by a code that was added by the research assistant. During the assessment sessions, full description references to both the King and the Lenke classification systems were provided to all three observers. To remove tool variability, the observers used the same type and brand of measurement and marker tools.

For the second part of the study, which was a diagnostic clinical trial, 20 patients who were classified using the Lenke classification method and 20 patients who were classified using the King classification method were followed after surgery. Both groups of patients were treated with CotrelDubousset instrumentation. The technique used was based on that of Dubousset and Cotrel. ${ }^{4}$ The patients were followed after surgery to assess treatment efficacy and complications.

Data were analyzed using SPSS software (SPSS Inc, Chicago, IL). The agreement among the observers was assessed using kappa coefficients of agreement. Postoperative results were compared using bivariate tests for continuous and dichotomous outcomes as well as repeated measures analysis of variance. A $P$ value less than 0.05 was considered statistically significant.

The regional committee of ethics of the Tabriz University of Medical Sciences approved the study. AA defended the study as the thesis work for a degree of specialty in orthopedics.

\section{Results}

\section{Background and interobserver reliability}

Of the 40 patients whose radiographs were studied, 16 (40\%) were male. The mean age of the participants was 15.3 years (standard deviation $[\mathrm{SD}]=2.1$ ). The youngest subject was 12 years of age; the oldest was 21 years of age.

A low to moderate interobserver agreement was observed for the King classification. Kappa coefficients of agreement were $0.16,0.24$, and 0.56 respectively for $1 \mathrm{st}-2 \mathrm{nd}, 2 \mathrm{nd}-3 \mathrm{rd}$, and 1 st-3rd observer comparisons $(P<0.05)$. Regarding the Lenke classification, kappa coefficients of agreement on curve assessment were $0.96,0.96$, and 1 for the three possible paired comparisons of observers $(P<0.05)$. Kappa coefficients of agreement on kyphosis assessment were complete for 1 st-2nd, 2nd-3rd, and 1st-3rd observer comparisons, and kappa coefficients of agreement on coronal curve assessment were similarly above 0.92 for all three paired comparisons of observers $(P<0.05)$.

\section{Postoperative comparisons}

Twenty patients were in the Lenke classification group, and half of these were females. Twenty patients were in the King classification group, and $70 \%$ of these were female. The mean age of patients classified through the Lenke classification method was 14.3 years $(\mathrm{SD}=1.7)$, and the mean age of those classified through the King classification method was 16.1 years $(\mathrm{SD}=3.1)$. Detailed classification figures, compared between males and females, are given in Table 1.

Surgical complications were encountered in two patients in the Lenke classification group and in three patients in the King classification group. The infectious complications were only surgical wound infections. There were no cases of mortality among the patients classified by the Lenke classification method, compared with two mortal cases in the King classification group. One person in each group needed to undergo another operation. No statistically significant difference was observed in the comparisons mentioned.

Figure 1 shows the comparison of Cobb angle, curve deviation at flexion, and apical rotation between the Lenke 
Table I Results of classification systems compared between genders

\begin{tabular}{llll}
\hline Classification & Type & Male [n (\%)] & Female [n (\%)] \\
\hline King (curve type) & $\mathrm{I}$ & $2(12.5)$ & NR \\
& 2 & $1(6.2)$ & $3(12.5)$ \\
& 3 & $6(37.5)$ & $10(41.7)$ \\
Lenke (curve type) & I & $3(18.8)$ & $5(20.8)$ \\
& 2 & $2(12.5)$ & $6(25)$ \\
& 3 & $2(12.5)$ & NR \\
& 4 & $7(25)$ & $9(27.5)$ \\
Lenke lumbar spine & $\mathrm{NR}$ & $2(8.3)$ \\
modifier & $\mathrm{A}$ & $2(12.5)$ & $4(16.7)$ \\
& $\mathrm{B}$ & $\mathrm{I}(6.2)$ & $4(16.3)$ \\
& $\mathrm{C}$ & $2(12.5)$ & $3(12.5)$ \\
& $-\left(<10^{\circ}\right)$ & $8(50.5)$ & $9(37.5)$ \\
& $+\left(>40^{\circ}\right)$ & $3(18.8)$ & $7(29.2)$ \\
& $\mathrm{Normal}$ & $5(31.3)$ & $8(33.3)$ \\
& $\left(10^{\circ}-40^{\circ}\right)$ & & $3(12.5)$ \\
\hline
\end{tabular}

Abbreviation: NR, not reported.

and King classifications prior to surgery. Trend of correction in curve deviation and apical rotation over time is given in Table 2. Both the difference in measures for gender and their trend over time in both groups were found to be different statistically significant.

Cobb angle (as mean plus or minus SD) decreased from $29.6^{\circ} \pm 7.4^{\circ}$ to $24.1^{\circ} \pm 6^{\circ}$ among male patients $(P<0.001)$. It decreased from $19.5^{\circ} \pm 4.1^{\circ}$ to $13.1^{\circ} \pm 2.7^{\circ}$ among female patients $(P<0.001)$.

\section{Discussion}

The present study did not find the surgery outcomes to be different between the two systems. In a study on 44 patients, Lenke et $\mathrm{al}^{5}$ concluded that the Lenke classification method

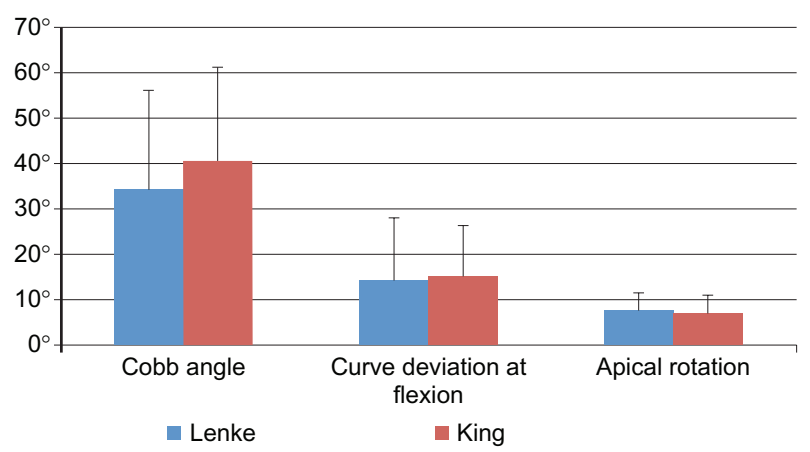

Figure I Comparison of Cobb angle, curve deviation at flexion, and apical rotation between the Lenke and the King classification systems prior to surgery.

Notes: Bars indicative of mean and skewers show standard deviation; observed differences were not statistically significant.
Table 2 Trend of correction in curve deviation and apical rotation (degrees) over time

\begin{tabular}{llllc}
\hline Gender & \multicolumn{4}{l}{ Curve deviation } \\
\cline { 2 - 5 } & $\begin{array}{l}\text { Before } \\
\text { surgery }\end{array}$ & $\begin{array}{l}\text { Month 3 } \\
\text { correction* }\end{array}$ & $\begin{array}{l}\text { Month 6 } \\
\text { correction* }\end{array}$ & $\begin{array}{l}\text { Month I2 } \\
\text { correction* }\end{array}$ \\
\hline Male & $21.3 \pm 16.2$ & $9.7 \pm 8.7$ & $10.3 \pm 8.9$ & $10.3 \pm 9.1$ \\
Female & $10.4 \pm 6.6$ & $4.7 \pm 3.4$ & $5 \pm 3.5$ & $5.2 \pm 3.5$ \\
& Apical rotation & & \\
Male & $9.2 \pm 4.5$ & $5 \pm 3.9$ & $4.9 \pm 3$ & $4.9 \pm 2.9$ \\
Female & $6.3 \pm 3.1$ & $2.4 \pm 1.5$ & $2.7 \pm 1.4$ & $2.9 \pm 1.6$ \\
\hline
\end{tabular}

Notes: Data are presented as mean plus or minus standard deviation; all observed differences between genders were statistically significant at $P<0.05$; *the difference from baseline (before surgery).

was advantageous. However, in the present study, in case of surgical outcome comparisons, the Lenke classification method was not found to be preferable to the King classification method. Schwab et $\mathrm{l}^{6}$ studied 111 patients for at least 1 year and found that classification modifiers had significant variation (higher rates) in surgical care as the grade of the modifier increased. The present study did not show a statistically significant difference in Cobb angle correction between the two groups; however, both groups showed a reduction of approximately $51 \%$ in Cobb angle postoperatively. Using the Lenke classification method, Han et $\mathrm{al}^{7}$ reported a reduction in Cobb angle of $68 \%$, which was a greater improvement than that found in the present study. The infectious complications in the present study were only surgical wound infections, while Xu et a ${ }^{8}$ reported pleural effusion, mesenteric artery ischemia, wound infection, and loosening of implants. Using the Lenke classification method, $\mathrm{Xu}$ et $\mathrm{al}^{8}$ also reported the average postoperative Cobb angle to be approximately $18.5^{\circ} .{ }^{8}$ In the present study, the were no cases of mortality among patients classified by the Lenke classification method, compared with two mortal cases in the King classification group. Although this was not statistically different between groups, the authors consider two cases are too few to provide enough statistical power to defend the similarity. However, this does raise some concern in the use of the King classification method and this should be addressed carefully in future studies.

Other than the role of these classification systems on predicting the surgery outcome, some studies have compared the interobserver reliability of the Lenke classification with that of the King classification. Although postoperative results were not much different, the findings of the present study indicated that the Lenke classification method provided more reliable classifications than the King 
Table 3 Conclusions made by studies assessing reproducibility of the King or the Lenke classification method in adolescent idiopathic scoliosis

\begin{tabular}{|c|c|c|}
\hline Study & Method & Conclusion \\
\hline Behensky et $\mathrm{al}^{9}$ & King vs Coonrad & $\begin{array}{l}\text { Neither the King nor the Coonrad classification method appeared to have sufficient } \\
\text { interobserver reliability; thus, the recommendation that, to improve reliability, the } \\
\text { structural stigmas of the upper thoracic and lumbar curves be unequivocally described }\end{array}$ \\
\hline Cummings et al ${ }^{10}$ & King & $\begin{array}{l}\text { The King classification method was found to be substantially reproducible } \\
\text { but only moderately reliable }\end{array}$ \\
\hline Sheng et al" & King, PUMC, Lenke & $\begin{array}{l}\text { The King and PUMC classification systems were found to have higher inter- and } \\
\text { intraobserver reliability than the Lenke classification method; the reliability levels } \\
\text { of the three classification systems were all found to be influenced by many factors }\end{array}$ \\
\hline Lenke et $\mathrm{al}^{12}$ & King & $\begin{array}{l}\text { The King method for classification of adolescent idiopathic scoliosis did not appear } \\
\text { to have sufficient intra- or interobserver reliability among scoliosis surgeons to portray } \\
\text { curve types accurately; thus, it was concluded that the King classification method } \\
\text { may not help to guide treatment with use of modern spinal fixation methods }\end{array}$ \\
\hline Ogon et $\mathrm{al}^{13}$ & King vs Lenke & $\begin{array}{l}\text { The Lenke classification method was found to be more reliable than the older King } \\
\text { classification method, but proper classification of high thoracic and lumbar curves } \\
\text { was found to be difficult }\end{array}$ \\
\hline Qui et $\mathrm{al}^{14}$ & Lenke vs PUMC & $\begin{array}{l}\text { The reliability of both the PUMC and the Lenke classification systems was categorized } \\
\text { as good to excellent; the PUMC classification method was found to be relatively } \\
\text { simple, with less confusion among inter- and intraobservers, with corresponding } \\
\text { surgical fusion guidance and planning }\end{array}$ \\
\hline Richards et al ${ }^{15}$ & Lenke vs King & $\begin{array}{l}\text { The King classification method was found to be better than had recently been reported; } \\
\text { the Lenke classification method for adolescent idiopathic scoliosis was found to be less } \\
\text { reliable than previously reported when the radiographs were premeasured }\end{array}$ \\
\hline
\end{tabular}

Abbreviations: PUMC, Peking Union Medical College; vs, versus.

classification method. Table 3 compares related studies and shows some controversies in the various reliability assessment results.

The present study had some limitations. Although enough statistical power was reached for the first part of the study (reliability), some postoperative outcomes, such as mortality, that were not found to be statistically different between the Lenke and King classification systems in the second part of the study might have suffered lower statistical power. This should be considered when interpreting the results of the second part of the study.

\section{Conclusion}

Based on the results, the Lenke classification method seems advantageous. This takes into consideration the Lenke classification method's priority in providing details of curvatures in different anatomical surfaces to explain precise intensity of scoliosis, that it has higher interobserver agreement scores, and also that it leads to noninferior postoperative results compared with the King classification method.

\section{Disclosure}

The authors report no conflicts of interest in this work.

\section{References}

1. Lonstein J. Idiopathic scoliosis. In: Lonstein J, Bradford D, Winter R, Ogilvie J, editors. Moe's Textbook of Scoliosis and Other Spinal Deformities. 3rd ed. Philadelphia: WB Saunders Co; 1995: 219-256.

2. Canale S. Campbell's Operative Orthopaedics. 9th ed. Philadelphia: Mosby; 1998.

3. Raggio CL. Sexual dimorphism in adolescent idiopathic scoliosis. Orthop Clin North Am. 2006;37(4):555-558.

4. Dubousset J, Cotrel Y. Application technique of Cotrel-Dubousset instrumentation for scoliosis deformities. Clin Orthop Relat Res. 1991;(264):103-110.

5. Lenke LG, Edwards CC 2nd, Bridwell KH. The Lenke classification of adolescent idiopathic scoliosis: how it organizes curve patterns as a template to perform selective fusions of the spine. Spine (Phila Pa 1976). 2003;28(20):S199-S207.

6. Schwab F, Lafage V, Farcy JP, et al. Surgical rates and operative outcome analysis in thoracolumbar and lumbar major adult scoliosis: application of the new adult deformity classification. Spine (Phila Pa 1976). 2007; 32(24):2723-2730.

7. Han IH, Chin DK, Kim KS. Short segment anterior correction of adolescent idiopathic scoliosis. J Korean Neurosurg Soc. 2008;44(1): $52-56$.

8. Xu RM, Sun SH, Ma WH, et al. Analysis of complications in scoliosis surgery. Zhongguo Gu Shang. 2008;21(4):245-248. Chinese.

9. Behensky H, Giesinger K, Ogon M, et al. Multisurgeon assessment of coronal pattern classification systems for adolescent idiopathic scoliosis: reliability and error analysis. Spine (Phila Pa 1976). 2002; 27(7):762-767.

10. Cummings RJ, Loveless EA, Campbell J, Samelson S, Mazur JM. Interobserver reliability and intraobserver reproducibility of the system of King et al. for the classification of adolescent idiopathic scoliosis. J Bone Joint Surg Am. 1998;80(8):1107-1111. 
11. Sheng WB, Zheng XF, Guo HL, et al. Intraobserver and interobserver reliability of the King, Lenke, and PUMC classification systems for idiopathic scoliosis. Zhonghua Yi Xue Za Zhi. 2009;89(15):1047-1052. Chinese.

12. Lenke LG, Betz RR, Bridwell KH, et al. Intraobserver and interobserver reliability of the classification of thoracic adolescent idiopathic scoliosis. J Bone Joint Surg Am. 1998;80(8):1097-1106.

13. Ogon $\mathrm{M}$, Giesinger $\mathrm{K}$, Behensky $\mathrm{H}$, et al. Interobserver and intraobserver reliability of Lenke's new scoliosis classification system. Spine (Phila Pa 1976). 2002;27(8):858-862.
14. Qui G, Li Q, Wang Y, et al. Comparison of reliability between the PUMC and Lenke classification systems for classifying adolescent idiopathic scoliosis. Spine (Phila Pa 1976). 2008;33(22):E836-E842.

15. Richards BS, Sucato DJ, Konigsberg DE, Ouellet JA. Comparison of reliability between the Lenke and King classification systems for adolescent idiopathic scoliosis using radiographs that were not premeasured. Spine (Phila Pa 1976). 2003;28(11):1148-1156.

\section{Publish your work in this journal}

The International Journal of General Medicine is an international, peer-reviewed open-access journal that focuses on general and internal medicine, pathogenesis, epidemiology, diagnosis, monitoring and treatment protocols. The journal is characterized by the rapid reporting of reviews, original research and clinical studies across all disease areas.

\section{Dovepress}

A key focus is the elucidation of disease processes and management protocols resulting in improved outcomes for the patient.The manuscript management system is completely online and includes a very quick and fair peer-review system. Visit http://www.dovepress.com/ testimonials.php to read real quotes from published authors.

Submit your manuscript here: http://www.dovepress.com/international-journal-of-general-medicine-journal 